\title{
Adélia Prado e Clarice Lispector: Teologia, Corporeidade, Eros e Ágape
}

\section{Adélia Prado and Clarice Lispector: theology, corporeity, eros and agape}

\author{
José Ernesto de Vargas* \\ Erik Dorff Schmitz**
}

Recebido: 17/09/2018. Aprovado: 26/04/2019.

Resumo: O presente artigo analisa e relaciona alguns temas levantados nas obras de duas escritoras brasileiras: Adélia Prado e Clarice Lispector. Para isso tomamos como base a publicação de Maria Clara Bingemer "Teologia e Literatura: afinidades e segredos compartilhados”, criando um diálogo entre teologia e literatura. Os temas que escolhemos para analisar e relacionar são: teologia, corporeidade, eros e ágape. Estes elementos estão presentes na vivência cotidiana, nos sentimentos e emoções humanas e são temas de tratados e produções no âmbito da teologia e da literatura. Nosso objetivo é destacar esses temas e mostrar como eles se relacionam e sugerem novas percepções da vida humana no atual momento do mundo, uma abordagem teológica mais antropológica, integradora da natureza humana e a união harmoniosa entre eros e ágape como elementos naturais da sexualidade do ser humano.

Palavras-chave: Literatura e Teologia. Deus. Corporeidade. Eros. Ágape.

Abstract: This article relates the themes raised in the works of two Brazilian women writers: Adélia Prado and Clarice Lispector. For this we take as base the publication of Maria Clara Bingemer "Theology and Literature: Affinities and shared secrets", creating a dialogue between theology and literature. The themes we choose to analyze and relate to are: corporeity, eros and agape. These elements are present in daily living, in human feelings and emotions and are subjects of treatises and productions in the scope of theology and literature. Our

* Doutor em Literatura (Universidade Federal de Santa Catarina, Florianópolis, 2008). Graduado em Letras (Universidade Federal do Rio Grande do Sul, Porto Alegre, 1992); E-mail: jedevargas@gmail.com

** Bacharel em Filosofia (Faculdade São Luiz, Brusque, 2011). Bacharel em Teologia (Faculdade Católica de Santa Catarina, Florianópolis, 2015). Mestrando em Literatura (Universidade Federal de Santa Catarina, Florianópolis).

E-mail: erik.schmitz@hotmail.com 
objective is to highlight these themes and to show how they relate, and suggest new perceptions of human life in the current moment of the world, is to show the themes as they relate to and promote new perceptions of human life and a harmonious union between human beings and natural as the sexuality of the human being.

Keywords: Literature and Theology. God. Corporeity. Eros. Agape.

\section{Introdução: Poesia, espiritualidade, teologia}

As reflexões entre literatura e teologia levantam questões inerentes aos seres humanos inquietados pela questão de um Mistério de Sentido em meio aos desafios da vida. Maria Clara Bingemer traz recentemente essa reflexão entre literatura e teologia, escrevendo sobre obras de escritores brasileiros e europeus que andam nesse limiar da arte poética e da reflexão teológica.

Poesia vem do grego poíesis, que significa "ação de fazer algo". Poesia, portanto, é práxis, apesar de ser a mais gratuita das práxis.

Espiritualidade vem de espírito, definido como a parte incorpórea, inteligente ou sensível do ser humano; o pensamento, a mente. Espiritual seria então o incorpóreo, o imaterial, sintonizado com o mistério, o místico, o sobrenatural.

Teologia, por sua vez, vem do grego theología, "ciência dos deuses". Pode ser o estudo das questões referentes ao conhecimento da divindade, de seus atributos e relações com o mundo e com os homens, e à verdade religiosa. Em segundo lugar, pode significar igualmente o estudo racional dos textos sagrados, dos dogmas e das tradições do cristianismo. Pode ser ainda um tratado ou compêndio sobre as verdades da fé; ou o conjunto de conhecimentos relativos aos dogmas de fé, ou que tem implicações com o pensar teológico, ministrados em cursos ou nas respectivas faculdades.

Esse três termos estão inter-relacionados e tocam uns aos outros em momentos tanto de reflexão como de práxis cotidiana. Podemos criar arte literária sem estarmos preocupados com uma reflexão teológica, mas mesmo assim adentrarmos nas beiradas desta. Podemos ter espiritualidade e ser muito espirituais em uma reflexão ou atitude cotidiana diante dos outros, sem possuir nenhum conhecimento teológico acadêmico. Como também podemos ser pessoas muito religiosas e termos conhecimentos 
de dogmas teológicos sem possuirmos realmente em nós muita mística ou espiritualidade cotidianas.

Queremos relacionar nas obras dessas autoras - Adélia e Clarice - como as duas criações - teologia e literatura - estão intrinsicamente relacionadas na criação textual, intelectual e mística de ambas.

\section{Adélia Prado: mulher, mãe e mística}

A poesia de Adélia Prado deixa notar uma intimidade e proximidade explícitas com o mistério divino. A poesia de Adélia é crente. Mas de uma crença que não pretende nem "consegue" ser convencionalmente litúrgica ou teológica ou catequística ou religiosa no sentido mais tradicional do termo. Pelo contrário. A fé e a crença que perpassam o discurso poético em Adélia Prado transitam nas áreas mais puramente humanas da vida cotidiana e ali descobrem e dizem o transcendente, presente em epifania e diafania ${ }^{1}$.

Lendo algumas de suas criações vemos como a crença e fé de uma mulher - esposa de José e mãe de cinco filhos, professora e formada em filosofia, catequista e católica - perpassa as linhas dos seus textos. Para ela Deus é Palavra antes do nome:

Não me importa a palavra, esta corriqueira.

Quero é o esplendido caos de onde emerge a sintaxe,

Os sítios onde nasce o "de", o "aliás", o "o", o "porém" e o "que", esta incompreensivel

muleta que me apoia.

Quem entender a linguagem entende Deus

cujo Filho é Verbo. Morre quem entender.

A palavra é disfarce de uma coisa mais grave, surda-muda, foi inventada para ser calada

Em momentos de graça, infrequentíssimos,

Se poderá apanhá-la: um peixe vivo com a mão.

Puro susto e terror. ${ }^{2}$

Percebe-se nesse poema uma chave primordial para começar a percorrer a trajetória de Deus na poesia adeliana. Para Adélia, Deus é mistério santo, reservado e revelado, que se entrega na mesma medida

BINGEMER, 2015, p. 25-26.

2 PRADO, 1999b, p. 22. 
em que se esconde. Que, inapreensível pela indústria humana, pronuncia sobre o "esplêndido caos" primigênio a palavra assistida pelo sopro do Espírito, fazendo emergir as coisas que não são para que sejam. A inspiração poética adeliana é, consciente e assumidamente, inspiração divina. Antes do nome, portanto, está o Nome que a tudo nomeia e que por nada nem ninguém pode ser nomeado. Nó de relações aberto ao mundo, aos outros, a Deus, o ser humano vive tensionado como arco cuja flecha mira o infinito, lutando com o peso da gravidade que o conduz ao chão, onde partilha com os outros seres criados a condição perecível e o destino mortal. ${ }^{3}$ Nesse poema vemos claramente intrincados os elementos teológicos e espirituais que Adélia consegue expressar em letra, frase e forma. Não são conjecturas teológicas, dogmáticas, catequéticas frias e estanques. Também não é uma piedade popular tradicional. É a mística interna de uma mulher concretizada em sua vida, e transcrita em literatura.

Outro elemento que podemos pôr em evidência é a importância da corporeidade para Adélia Prado. Lemos o poema "O aprendiz de ermitão":

É muito difícil jejuar

Com a boca decifro o mundo, proferindo palavras,

Beijando os lábios de Jonathan que me chama Primora,

Nome de amor inventado.

Flauta com a boca se toca,

Do sopro de Deus a alma nasce,

Dor tão bonita que eu peço:

Dói mais, um pouquinho só.

Não me peça de volta o que me destes, Deus.

Meu corpo de novo é inocente,

Como a pastos sem cerca amo Jonathan,

Mesmo que me esqueça.

Ô mundo bonito!

Eu quero conhecer quem fez o mundo

Tão concertadamente descuidoso.

Os papagaios falam, Jonathan respira

E tira do seu alento este som: Primora.

'Tomai e comei."

Vosso Reino é comida?

Eu sei? Não sei.

Mas tudo é corpo, até vós,

3 BINGEMER, 2015, p. 28-29. 
Mensurável matéria.

O espírito busca palavras,

Quem não enxerga ouve sons,

Quem é surdo vê luzes,

O peito dispara a pique de arrebentar.

Salve mistérios! Salve mundo!

Corpo de Deus, boca minha,

Espanto de escrever, arriscando minha vida:

Eu te amo, Jonathan,

Acreditando que você é Deus e

Me salvará a palavra dita por sua boca.

Me saúda assim como à Aurora Consurgens:

Vem, Primora.

Falas como um homem,

Mas o que escuto é o estrondo

Que vem do Setentrião.

Me dá coragem, Deus, para eu nascer. ${ }^{4}$

Centrado no mistério da encarnação, na realidade o cristianismo não menospreza o corpo, mas o inclui em sua reflexão e em seu discurso e o situa em lugar proeminente ao refletir e falar sobre o mistério do divino. A experiência da transcendência do cristianismo é a experiência de um Deus encarnado. A partir dessa convicção central cristã - de que o corpo humano é condição de possibilidade da encarnação e, sobretudo, da experiência do divino - a poesia feminina de Adélia Prado adquire, aos olhos da teologia, uma luminosidade toda especial. Aqui está o eixo central que rege toda a sua obra, seja em poesia ou em prosa. ${ }^{5}$

Adélia não cessa de redimir e louvar o corpo humano, na sua busca incessante de comunhão com Deus:

É inútil o batismo para o corpo...

O corpo não tem desvãos,

Só inocência e beleza

Tanta que Deus nos imita

E quer casar com sua Igreja. ${ }^{6}$

Na relação entre os corpos masculinos e femininos há a fusão de amor que transubstancia o carinho em liturgia e a sexualidade em fonte

4 PRADO, 1999a, p. 422.

5 BINGEMER, 2015, p. 35-36.

6 PRADO, 1999a, p. 320. 
prazerosa de vida. A beleza da encarnação do Verbo que habitou entre nós é sentida no corpo. A beleza e a transcendência podem ser encontradas na carne, no corpo, no homem e na mulher.

Com isso vemos que ao mesmo tempo em que se dá conta das vicissitudes de ser humana, de ser corpórea, de ser mulher, Adélia se revela alguém plenamente reconciliada com seu corpo feminino, incluídos aí seus ciclos e particularidades.

A poesia de Adélia Prado, ainda que sem uma intencionalidade explícita, questiona frontalmente a concepção negativa que a moral cristã coloquialmente rígida e escrupulosa fez da corporeidade feminina. Vejamos:

\author{
Mais que Javé na montanha \\ esta revelação me prostra. \\ Ó mistério, mistério \\ suspenso no madeiro \\ o corpo humano de Deus. É próprio do sexo \\ $o$ ar \\ que nos faunos velhos surpreendo, \\ em crianças supostamente pervertidas \\ e a que chamam dissoluto. \\ Nisto consiste o crime, \\ em fotografar uma mulher gozando \\ e dizer: eis a face do pecado. \\ Por séculos e séculos \\ os demônios porfiaram \\ em nos cegar com este embuste. ${ }^{7}$
}

O Espírito é buscado e experimentado na carne - eis uma constante na poesia de Adélia. A origem dessa convicção é simples e cristalina: Deus não rejeita a obra de suas mãos. Simplesmente não é possível que nos haja criado bons para rejeitar-nos depois como se fôssemos maus, e condenar como coisa pecaminosa e impura o nosso corpo que nos deu com seu amor criativo. ${ }^{8}$

Corporeidade, eros e ágape estão imersos nas obras de Adélia. Para ela Deus e poesia se confundem, um é o nome da outra e a outra revela o nome do Um. Este giro poético é comandado por uma dinâmica

7 PRADO, 1999a, p. 281.

8 Cf. BINGEMER, 2015, p. 45. 
erótica e amorosa onde os parceiros são carregados pelo amor que os possui e pelo qual são tomados. Em Adélia, mística e erótica se tocam e até mesmo se confundem. ${ }^{9}$

Afirmamos assim que tudo o que revela a experiência mística e espiritual está constituído do mais humano da nossa corporeidade. Amor, sexo, prazer, masculino e feminino são o lugar mais apropriado onde Deus se faz presente para fundir em nós sua energia vital. Sem estes elementos não somos humanos, e Deus não pode em nós ser divino.

\section{Clarice Lispector: tensão entre eros e ágape}

Analisando e trazendo dois elementos das obras de Clarice Lispector - eros e ágape - sentimos as relações que esses dois elementos tem com a teologia e a mística. Clarice em dois romances - Uma aprendizagem ou O livro dos prazeres (1969) e em A paixão segundo G.H. - mostra como nessa mulher judia e de fé, de cuja escrita jorra a palavra Deus, há uma sensibilidade espiritual imensa para qualquer manifestação da transcendência que possa acontecer em todas as dimensões da existência humana.

Eros significa o desejo amoroso e sexual. Ocupa um lugar importante no pensamento religioso, na vida social, assim como na arte e na literatura dos gregos. No campo da teologia, pelo menos na corrente que predominou no universo cultural do Ocidente, prevaleceu a concepção de eros como força perturbadora, ligada apenas a uma concepção negativa $\mathrm{e}$ distorcida do sexo. Contribui para isso, certamente, o outro nome dado ao mesmo amor que o cristianismo, notadamente o Novo Testamento, cunhou como a nomeação de Deus por excelência: ágape. Mas em vinte séculos de cristianismo a teologia e a mística cristãs não resolveram, de maneira integradora e satisfatória, seu problema com a relação do eros com a ágape

Certas tradições cristãs mais antigas e até recentes tem se caracterizado por colocar sob suspeita aquilo que diz respeito ao Eros, incutindo isso na mentalidade das pessoas e criando repressões exageradas. Vejamos como a mística expressa nas obras de Clarice nos ajuda a retirar de nossas mentes essas concepções não saudáveis criadas ao longo do cristianismo.

O livro dos prazeres baseia-se na história de Loreley, cujo apelido é Lóri, professora primária que passa a viver no Rio de Janeiro após

9 Cf. BINGEMER, p. 52-53. 
sair de casa de seus pais, em Campos. Ela conhece Ulisses, professor de filosofia, numa noite em que esperava um táxi e ele lhe ofereceu carona. A partir daí, após ter tido outras experiências amorosas, sente que esta era realmente verdadeira. Ela amava pela primeira vez e tinha que passar pelo processo de aprendizagem desse novo sentimento, o qual tinha de aceitar ${ }^{10}$.

O olhar da teologia, debruçado sobre a obra literária de Clarice, percebe o processo de iniciação amorosa que vai ser narrado como algo para além do mero encontro físico e apaixonado de um homem e de uma mulher. Trata-se de um processo de encontro profundo entre dois seres humanos, e, mais que isso e para além disso, de um encontro com o mistério. Que nome terá esse mistério? Em todos os casos, como afirma a própria Clarice antes do começo da narrativa, trata-se de um mistério maior, um mistério que está acima: "Este livro se pediu uma liberdade maior que tive medo de dar. Ele está acima de mim. Humildemente tentei escrevê-lo. Eu sou mais forte do que eu"11. Ao mesmo tempo o mistério maior e mais alto que pediu uma liberdade que provoca medo suscitou o sentimento da humildade e a atitude da obediência que consente em tomar da pena e escrever. E, ao curvar a cabeça e obedecer à inspiração, percebe ser mais forte que si mesma. Parece-nos que Clarice anuncia aí o drama e a beleza próprios da condição humana, de ser finitude, morada do infinito e do incondicionado. E de encontrar sua força e alegria em obedecer a Outro que o institui como aquilo que é: ser mortal criado para a vida. ${ }^{12}$

Eros e ágape se dão as mãos no itinerário de Lóri e Ulisses. E a espera que se prolonga e que é sofrida, mas pedagógica para ambos, esbarra em Deus, que se torna tema de conversa dos dois:

- Deus não é inteligente, compreende, porque Ele é a Inteligência, Ele é o esperma e óvulo do cosmos que nos inclui. Mas eu queria saber por que você, em vez de chamar Deus, como todo o mundo, chama o Deus? - Porque Deus é um substantivo.

- É a professora primária que está falando.

\footnotetext{
10 Cf. BINGEMER, 2015, p. 78.

11 LISPECTOR, 1969.

12 Cf. BINGEMER, 2015, p. 80-81.
} 
- Não, Ele é substantivo como substância. Não existe um único adjetivo para o Deus. "Vós sois deuses." Mas éramos deuses com adjetivos. ${ }^{13}$

O encontro amoroso definitivo entre os dois se dá cercado de ritualidade, mas sem escrupulosidade, como convém a um amor verdadeiro e concreto, onde eros e ágape estão juntos. O beijo acontece com os dois ajoelhados um frente ao outro, em gesto mais que de satisfação de desejo, é de ação de graças:

Ela não soube como, de joelhos mesmo, ele a tinha feito ajoelhar-se junto a ele no chão, sem que ela sentisse constrangimento. E uma vez os dois ajoelhados, ele enfim a beijou. Ele a beijou demoradamente até que ambos puderam se deslocar um do outro, e ficaram se olhando sem pudor um nos olhos do outro. ${ }^{14}$

Assim vemos de forma mística, ritual e podemos dizer sagrada, a intenção de Clarice em pôr eros e ágape no mesmo patamar, sem negatividade. A busca do eros é uma viagem de iniciação ao encontro com o outro, se fazendo aprendizagem do viver e do ser, sob a presidência do amor e liberdade dada por Deus.

Outro romance de Clarice que queremos pôr em evidência é $A$ paixão segundo G.H., de 1964. Nesse romance, Clarice Lispector consegue transmitir ao leitor as preocupações de ordem emocional da personagem G.H., uma mulher bem-sucedida profissionalmente, de vida confortável e abastada, mas que não conhece a sua própria identidade e, por isso, vai em busca do conhecimento interior. Depois de despedir a empregada, G.H. vai fazer uma faxina no quarto de serviço. Mal começa a limpeza, se depara com uma barata. Ela esmaga o inseto contra a porta do armário. Depois, numa espécie de ascese, decide provar a barata morta. Ao esmagar a barata, e depois degustar seu interior branco operou-se nela uma revelação.

Ao ler o romance podemos perceber que a mulher burguesa que é G.H. se sente como num deserto, sem organização ou ordem que lhe dê harmonia, sem mão para segurar que lhe dê alegria. A ida para o quarto da empregada na verdade é uma descida, uma descida kenótica. Ao entrar no humilde quartinho da empregada, G.H. percebe que entra em outro mundo. Onde esperava encontrar escuridão, desordem, sujeira, mofo,

\footnotetext{
13 LISPECTOR, 1969, p. 133.

14 LISPECTOR, 1969, p. 148-149.
} 
G.H. depara-se com algo totalmente inesperado: reinam uma ordem e uma claridade absolutas. ${ }^{15}$

Além disso podemos afirmar que a viagem de G.H., é considerada do ponto de vista teológico, uma viagem mística. Ou até mesmo "crística". Pois "crístico" é o movimento que faz o Filho de Deus ao não aferrar-se a suas prerrogativas e a esvaziar-se, despojar-se, humilhar-se, obediente até a morte, e morte de cruz. ${ }^{16}$

Mas onde está o impulso erótico, do eros, nessa personagem?

O encontro com a barata, seu esmagamento e a degustação dela não se resume a um desejo de morte (tanatos), mas frente a este impulso jorra o desejo da vida. G.H. tem uma crise e um renascimento de eros e ágape e mística, que lhe restitui a vida anímica que havia perdido.

Assim a presença de eros se dá atraindo G.H., mulher refinada e acostumada ao conforto e ao luxo, para o ponto mais baixo da vida: a substância, a "carne" de uma barata, coração da matéria, presença do caos em seu falsamente ordenado mundo. Por isso a barata a atrai e ela a compara luxuosamente a "uma noiva de pretas joias, toda rara" e sente que ela é "pura sedução". Tudo, porém, não acabou ali, havia agora que contemplar e sentir a proximidade da massa branca que saía da barata e convidava a gritar, para entrar na verdadeira vida. ${ }^{17}$

G.H. está renascendo! Entrando no mundo, dando-se à luz. A experiência mística de G.H., como a de todo ser humano, a faz vibrar de desejo de encontrar e experimentar o amor em sua vida.

Em ambas as obras de Clarice apresentam-se ao leitor experiências humanas profundas em que os dois dinamismos estão presentes de forma integrada e recíproca, gerando uma tensão dialética que é fecunda e verdadeira. Literatura e mística se entrecruzam.

\section{Adélia e Clarice: novas perspectivas para a teologia}

Em Adélia Prado e sua poesia encontramos a mística de uma mulher casada, católica e mãe, muito feminina e espirituosa, que imprime no texto as marcas do sagrado que há dentro de si: sagrado este que só

$\begin{array}{ll}15 & \text { Cf. BINGEMER, 2015, p. } 94 . \\ 16 & \text { Cf. BINGEMER, 2015, p. } 94 . \\ 17 & \text { Cf. BINGEMER, 2015, p. } 98 .\end{array}$ 
pode ser sagrado diante do humano com todas as suas realidades de corpo, mente e espírito. Eros e ágape, maternidade e feminilidade são saudáveis, agradáveis e vibrantes na pele, voz e escrita de Adélia.

Já em Clarice, mulher judia, que dá socos no estômago de seus leitores, as relações entre seus personagens se dá de forma mística e ritualizada, mas sem escrúpulos e rigidez. Todos passam por metamorfoses, crises, desertos, após alguns rodeios, mais cedo ou tarde desvendam o mistério que os importunava. Estes personagens envoltos em dor, solidão, crise e angústia encontram no eros e no ágape os elementos para viverem a mística espiritual que emana de Deus sem necessariamente viverem religiosamente.

Esses temas apresentados, eros e ágape, hoje necessitam de uma abordagem teológica nova diante da nova configuração de mundo. A Teologia em diálogo com a Literatura, abordagem já consolidada no âmbito acadêmico-científico, é um caminho de revisão de concepções ultrapassadas que não condizem mais com a realidade do século XXI. No mundo já liquefeito, onde novas e velhas ideologias ressurgem para construir novos muros, a Teologia presente na obra dessas duas escritoras é uma contracorrente às polarizações sociais, políticas e religiosas. A Teologia e a eclesiologia cristãs por séculos foram e continuam sendo permeadas pela divisão maniqueísta entre bem e mal, puro e impuro, limpo e sujo, o que ocasionou a formação da consciência ocidental em padrões rígidos e estanques, gerando muitas vezes preconceitos, injustiças e perseguições. Isto, por incrível que pareça, está presente hoje nos discursos cristãos, tanto pelos líderes religiosos, como pelos fiéis. Fonte de intolerância e intransigência, a criação de novos muros de divisão por questões relativas à sexualidade humana, comportamentos e diversidades - pelos cristãos mais fervorosos com pouca humanidade e espiritualidade realmente evangélica - é o que precisa ser enfrentado e derrubado. Esses muros não favorecem uma vivência minimamente saudável em sociedade, nos ambientes de trabalho e de estudo, religiosos e laicos.

Uma abordagem teológica mais antropológica, integradora da natureza humana, é o que está presente nas obras de Adélia e Clarice, e serve como exemplo de uma espiritualidade evangélica, um tanto afastada do ambiente eclesiástico, dogmático, canônico que muitas vezes está distante do espírito da mensagem da pessoa de Jesus e já não responde às angústias dos jovens, homens e mulheres, casais e famílias, e daqueles que sempre estiverem à margem dos padrões os religiosos de vida. 
O que necessitamos na educação e orientação dos cristãos e também não cristãos é simplesmente uma união harmoniosa entre éros e ágape como elementos naturais da sexualidade do ser humano. A partir dessa perspectiva, podemos construir uma mentalidade e uma psicologia do desenvolvimento humano mais integradoras em ordem crescente de virtudes, relacionamentos e progressos pessoais e sociais. A volta de discursos maniqueístas, conservadores, repressores e moralistas é um desserviço e retrocesso à humanidade e aos grupos humanos. Não cair na banalização do corpo e da subjetividade, mas também não voltarmos ao medievalismo ou puritanismo é o que as sociedades, o Brasil e o mundo necessitam em seus ambientes religiosos e laicos. Cabe aos líderes religiosos também desenvolverem uma mudança de mentalidade para melhor, arejando suas mentes e as mentes dos fiéis. Cabe aos cristãos, um olhar mais crítico e criativo diante de discursos políticos e religiosos que não contribuem mais para o desenvolvimento da pessoa e das sociedades humanas de forma integral.

Diante disso, afirmamos que, Deus, corporeidade, eros, ágape, estão presentes em ambas as escritoras e suas obras aqui abordadas. Relacionam-se e se entrecruzam, pois são elementos constitutivos da natureza humana. Adélia e Clarice, como mulheres místicas, expressam o que de mais humano e divino há dentro delas e de cada pessoa. Literatura e teologia, arte e mística estão presentes em nossas expressões cotidianas. São mais bem percebidas quanto menos rigidamente emolduradas e cerceadas. Expressam a beleza de Deus e do ser humano, e tudo o mais que escapa à nossa compreensão.

\section{Referências bibliográficas}

BINGEMER, Maria Clara. Teologia e Literatura: afinidades e segredos compartilhados. Petrópolis: Vozes, 2015.

LISPECTOR, C. Uma aprendizagem ou O livro dos prazeres. Rio de Janeiro: Sabiá, 1969.

. A paixão segundo G.H. Rio de Janeiro: Sabiá, 1964.

PRADO, Adélia. Poesia reunida. 8. ed. São Paulo: Siciliano, 1999a.

. Oráculos de maio. Rio de Janeiro: Record, 1999b. 